\title{
A numerical study on near-bed flow mechanisms around a marine pipeline close to a flat seabed including estimation of bedload sediment transport
}

\author{
M. C. Ong ${ }^{1}$, T. Utnes ${ }^{2}$, L. E. Holmedal ${ }^{1}$, D. Myrhaug ${ }^{1}$ \\ \& B. Pettersen ${ }^{1}$ \\ ${ }^{1}$ Department of Marine Technology, \\ Norwegian University of Science and Technology, Norway \\ ${ }^{2}$ SINTEF IKT Applied Mathematics, Norway
}

\begin{abstract}
Near-bed flow mechanisms of high Reynolds number flows around a marine pipeline close to a flat seabed have been studied using a two-dimensional standard high Reynolds number k- $\varepsilon$ model. The effects of gap to diameter ratio and seabed roughness for a given boundary layer thickness of the inlet flow upstream of the cylinder have been investigated. The vortex shedding mechanisms have been investigated. Mean pressure, mean friction velocity and the resulting mean bedload sediment transport along the bed have been predicted. Overall it appears that for engineering design purposes the present numerical model is suitable for predicting high Reynolds number flows, which are present near the seabed in the real ocean.
\end{abstract}

Keywords: numerical model, pipeline, flat seabed, high Reynolds number.

\section{Introduction}

Marine pipelines are widely used for transporting oil and gas from offshore fields. They are often subject to high Reynolds numbers flow with typical values of $\mathrm{O}\left(10^{4}\right)-\mathrm{O}\left(10^{7}\right)$, covering subcritical $\left(300<\operatorname{Re}<3 \times 10^{5}\right)$ to trancritical $(\operatorname{Re}>$ $4 \times 10^{6}$ ) flow regimes. Here $\operatorname{Re}=\mathrm{U}_{\infty} \mathrm{D} / v$ where $\mathrm{D}$ is the cylinder diameter; $\mathrm{U}_{\infty}$ is the free stream velocity; and $v$ is the kinematic viscosity. The hydrodynamic 
characteristics of steady flow around a horizontal smooth circular cylinder near a fixed horizontal boundary represent an idealized situation of a pipeline near the seabed. The proximity of the pipeline to the seabed affects the flows around the pipeline and along the seabed.

Several experimental studies have been carried out to investigate flows at high Reynolds numbers ranging from $\mathrm{O}\left(10^{4}\right)$ to $\mathrm{O}\left(10^{5}\right)$ in the subcritical flow regime (see, e.g., Bearman and Zdravkovich [1], Lei et al. [2] and Wang and Tan [3]). Bearman and Zdravkovich [1] investigated the influence of $\mathrm{G} / \mathrm{D}$ on the vortex shedding and its spectral behaviour with an upstream flow of $\delta / D=0.8$ at Re ranging from $2.5 \times 10^{4}$ to $4.8 \times 10^{4}$. Here $\mathrm{G}$ is the distance between the bottom of the cylinder and the bed, and $\delta$ is the boundary layer thickness of the inlet flow upstream of the cylinder (see fig. 1 for definitions). They measured the distributions of mean pressure around the cylinder and along the bed at $\mathrm{Re}=$ $4.8 \times 10^{4}$. They also showed that the vortex shedding motion behind a circular cylinder close to a flat bed is suppressed at $G / D<0.3$. Here the $G / D$ corresponding to the onset of vortex shedding is defined as the critical ratio, $\mathrm{G} / \mathrm{D}_{\mathrm{c}}$. Lei et al. [2] studied the flow around a smooth circular cylinder immersed in different boundary layer thicknesses $(\delta / \mathrm{D}=0.14-2.89)$ at Re ranging from $1.31 \times 10^{4}$ to $1.45 \times 10^{4}$. Their experimental results showed that both drag and lift coefficients strongly depend on G/D, and are affected by $\delta / D$. They found that the variation of the root-mean-square fluctuating lift coefficient $\left(\mathrm{C}_{\mathrm{Lrms}}\right)$ can be used to determine the suppression and onset of the vortex shedding. Their observations also showed that the vortex shedding is suppressed at G/D of 0.20.3 , depending on different $\delta / \mathrm{D}$. Wang and Tan [3] studied the near-wake flow characteristics of a circular cylinder close to a flat bed for $\mathrm{Re}=1.2 \times 10^{4}$ and $\delta / \mathrm{D}$ $=0.4$. Their results showed that instantaneous flow fields depend strongly on $\mathrm{G} / \mathrm{D}$, and that the flow is characterized by a periodic vortex shedding for $\mathrm{G} / \mathrm{D} \geq$ 0.3 .

Only a few numerical studies have been performed for such high Reynolds number flows $\left(\operatorname{Re}>10^{4}\right)$ around a circular cylinder near a plane wall. Brørs [4] and Zhao et al. [5] applied a standard high Reynolds number $\mathrm{k}-\varepsilon$ model at $\mathrm{Re}=$ $1.5 \times 10^{4}$ and a $\mathrm{k}-\omega$ model at $\mathrm{Re}=2 \times 10^{4}$, respectively. Their results yielded a good qualitative agreement with the published experimental data. However, detailed comparisons with experimental results for $\mathrm{G} / \mathrm{D}<0.4$ are not made. Recently Ong et al. [6] applied the standard high Reynolds number k- $\varepsilon$ model at $\operatorname{Re}=1 \times 10^{4}-4.8 \times 10^{4}$ with $\delta / \mathrm{D}=0.14-2$. Comparisons of numerical results with the published experimental data were provided for the cases of $\mathrm{G} / \mathrm{D}<0.4$. They found that under-predictions of the essential hydrodynamic quantities of the cylinder (such as $C_{D}, C_{L}, S t, C_{L r m s}$ and $C_{p}$ ) were observed in the subcritical flow regime due to the well-known limited capacity of the k- $\varepsilon$ model (and similar two-equation turbulence closures) to capture the vortex shedding correctly. Here $\mathrm{C}_{\mathrm{D}}$ is the time-averaged drag coefficient, $\mathrm{C}_{\mathrm{L}}$ is the time-averaged lift coefficient, $\mathrm{St}=\mathrm{fD} / \mathrm{U}_{\infty}$ is the Strouhal number (here $\mathrm{f}$ is the vortex-shedding frequency), and $\mathrm{C}_{\mathrm{p}}$ is the mean pressure coefficient around the cylinder. $\mathrm{C}_{\mathrm{D}}$ and $\mathrm{C}_{\mathrm{L}}$ are calculated based on the definitions $\mathrm{F}_{\mathrm{D}}=0.5 \rho \mathrm{DC}_{\mathrm{D}} \mathrm{U}_{\infty}{ }^{2}$ and $\mathrm{F}_{\mathrm{L}}=0.5 \rho \mathrm{CC}_{\mathrm{L}} \mathrm{U}_{\infty}{ }^{2}$, where $\mathrm{F}_{\mathrm{D}}$ and $\mathrm{F}_{\mathrm{L}}$ are the time-averaged integrated horizontal and vertical forces per unit length, 
respectively, acting on the cylinder; and $\rho$ is the fluid density. There is also a limitation of using two-dimensional (2D) models for three-dimensional (3D) flow, as effects from the spanwise secondary flow are not considered in the $2 \mathrm{D}$ simulation (see Mittal and Balachandar [7]). However, the mean pressure and the friction velocity along the bed were predicted reasonably well as compared with the published experimental and numerical results in the subcritical flow regime.

Ong et al. [8] and Catalano et al. [9] presented numerical results on flow around an isolated smooth circular cylinder subject to a steady current at $\mathrm{Re}$ ranging from $0.5 \times 10^{6}$ to $4 \times 10^{6}$ by using the standard high Reynolds number $\mathrm{k}-\varepsilon$ model. Overall, their results are in satisfactory agreement with published experimental data. To our knowledge, neither numerical nor experimental studies are available in the open literature for flows around a circular cylinder close to a flat seabed beyond the supercritical flow regime $\left(\operatorname{Re}>1 \times 10^{6}\right)$.

In the present study, the flows at $\operatorname{Re}=3.6 \times 10^{6}$ and $\delta / \mathrm{D}=0.48$ with two different seabed roughnesses $\left(\mathrm{z}_{\mathrm{w}}=1 \times 10^{-6} \mathrm{~m}\right.$ and $\left.2 \times 10^{-5} \mathrm{~m}\right)$ are investigated numerically by using 2D Unsteady Reynolds-Averaged Navier-Stokes (URANS) equations with a standard high Reynolds number $\mathrm{k}-\varepsilon$ model. Here $\mathrm{z}_{\mathrm{W}}=\mathrm{d}_{50} / 12$ where $d_{50}$ is the median grain size diameter. Effects of gap to diameter ratio and seabed roughness are investigated. Mechanisms of vortex shedding are investigated. Near-bed hydrodynamic quantities and the resulting bedload sediment transport are also predicted.

\section{Mathematical formulation}

\subsection{Flow model and numerical solution procedure}

The 2D URANS equations are solved using a standard high Reynolds number $k$ $\varepsilon$ model (see Launder and Spalding [10]) and a Galerkin finite element method with a Segregated Implicit Projection (SIP) solution algorithm proposed by Utnes [11]. This numerical method is $2^{\text {nd }}$ order both in time and space.

\subsection{Computational domain, boundary conditions and convergence studies}

The computational domain and the boundary conditions imposed for the present simulations are shown in fig. 1. The size of the whole computational domain is $30 \mathrm{D}$ by $10 \mathrm{D}$. The upper boundary is located at a distance varying from $8.5 \mathrm{D}$ to 9.4D from the centre of the cylinder depending on the corresponding gap ratio; this ensures that the boundary has no effect on the flow around the cylinder. The flow inlet is located 10D upstream from the centre of the cylinder and the flow outlet is located 20D downstream from the centre of the cylinder. These distances are sufficient to eliminate the far field effects from the flow upstream and downstream of the cylinder.

The boundary conditions used for the numerical simulations are as follows:

1. A boundary layer flow is specified at the inlet (see fig. 1)

$$
\begin{gathered}
u_{1}(Y)=\min \left\{u * \ln \left(Y / z_{w}\right) / \kappa, U_{\infty}\right\} ; \mathrm{u} 2(Y)=0 \\
k(Y)=\max \left\{C_{\mu}{ }^{-1 / 2}(1-Y / \delta)^{2} u^{2}, 0.0001 U_{\infty}{ }^{2}\right\} ; \varepsilon(Y)=C_{\mu}^{3 / 4} k(Y)^{3 / 2} / \ell
\end{gathered}
$$




$$
\ell(Y)=\min \left\{\kappa Y(1+3.5 Y / \delta)^{-1}, C_{\mu} \delta\right\}
$$

Here $\mathrm{Y}$ denotes the wall normal direction starting from the seabed (see fig. 1). $\mathrm{k}$ is the turbulent kinetic energy. $\varepsilon$ is the rate of viscous dissipation. $\mathrm{u}_{1}$ and $\mathrm{u}_{2}$ are the horizontal and vertical velocities, respectively. $C_{\mu}=0.09$ is one of the standard coefficients in the k- $\varepsilon$ model. The friction velocity is evaluated as $\mathrm{u}_{*}=\kappa \mathrm{U}_{\infty} / \ln \left(\delta / \mathrm{z}_{\mathrm{w}}\right)$, where $\mathrm{z}_{\mathrm{w}}$ is the roughness of the flat bed, and $\kappa=0.41$ is the von Kármán constant. $\ell$ is an estimate of the turbulent length scale (see e.g. Brørs [4]).

2. Along the outflow boundary, $\mathrm{u}_{1}, \mathrm{u}_{2}, \mathrm{k}$ and $\varepsilon$ are specified as free boundary conditions in a finite element context. This means that a traction-free velocity-pressure boundary condition is applied for $\mathrm{u}_{1}, \mathrm{u}_{2}$ and $\mathrm{P}$ (see Gresho and Sani [12] for details), while the flux is set equal to zero for $\mathrm{k}$ and $\varepsilon$. Along the upper boundary, $\mathrm{u}_{1}, \mathrm{k}$ and $\varepsilon$ are free, while $u_{2}$ is set equal to zero.

3. No-slip condition is applied on the cylinder surface and the seabed with $\mathrm{u}_{1}$ $=\mathrm{u}_{2}=0$.

4. Standard near-wall conditions are applied for $\mathrm{k}$ and $\varepsilon$ near the cylinder wall and the bed (see e.g. Rodi [13]) as

$$
k=u_{*}{ }^{2} /\left(C_{\mu}\right)^{1 / 2} ; \varepsilon=C_{\mu}^{3 / 4} k^{3 / 2} /\left(\kappa h_{p}\right)
$$

where $h_{p}$ is the normal distance between the first node and the wall, and $u *$ is the wall friction velocity obtained from the logarithmic (log) law.

$$
u_{\text {tan }} / u_{*}=(1 / \kappa) \ln \left(h_{p} / z_{*}\right) \quad \text { where } z_{*}=\left(z_{0}, z_{w}\right)
$$

Here $\mathrm{u}_{\mathrm{tan}}$ is tangential velocity to the wall, $\mathrm{z}_{0}$ is the roughness parameter of the cylinder surface and $\mathrm{Z}_{*}$ is a switch parameter for the wall roughness. A small roughness with $\mathrm{z}_{0}=1 \times 10^{-6} \mathrm{~m}$ (i.e. $\mathrm{d}_{50}=12 \mathrm{z}_{0}=0.012 \mathrm{~mm}$ ) is used for the cylinder for all the present simulations. This small roughness leads to almost the same results as a smooth logarithmic wall function, but is preferred because of enhanced numerical stability of the simulations.

Stretching of the mesh is performed to achieve a fine resolution of the region close to the cylinder surface and the seabed. When the grid is refined, the symmetrical grid elements nearest to the cylinder surface are kept constant. The

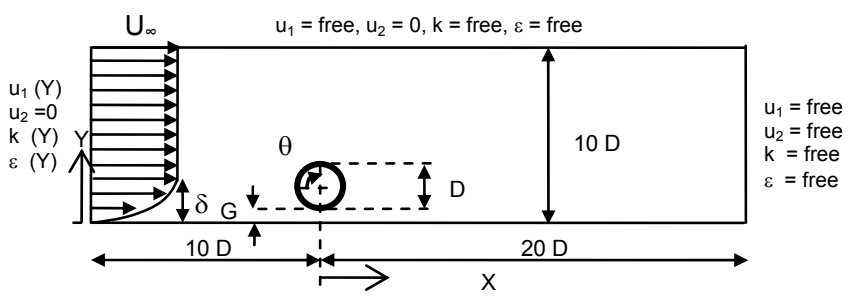

Figure 1: Definition sketch for flow around a circular cylinder close to a flat seabed. 
seabeds with small roughness $z_{\mathrm{W}}=1 \times 10^{-6} \mathrm{~m}$ and higher roughness $\mathrm{z}_{\mathrm{W}}=2 \times 10^{-5} \mathrm{~m}$ (i.e. $\mathrm{d}_{50}=12 \mathrm{z}_{\mathrm{w}}=0.24 \mathrm{~mm}$ ) are used.

Both grid and time-step convergence studies have been performed for flows at $\mathrm{Re}=3.6 \times 10^{6}$ for cases of $\delta / \mathrm{D}=0.48, z_{w}=\left(1 \times 10^{-6} \mathrm{~m}, 2 \times 10^{-5} \mathrm{~m}\right)$ and $\mathrm{G} / \mathrm{D}=(0.1$, $0.2,0.3,0.4,0.6,0.8,1)$. The variations of $C_{D}$ and $C_{L}$ are considered in both grid and time-step convergence studies with a converged deviation of less than $5 \%$. The meshes with approximately 40000 elements are considered to give a sufficient grid resolution, see fig. 2 for $\mathrm{Re}=3.6 \times 10^{6}$ with $\delta / \mathrm{D}=0.48$ and $\mathrm{z}_{\mathrm{w}}=$ $1 \times 10^{-6} \mathrm{~m}$. The radial distance to the first node from the cylinder surface is $0.0005 \mathrm{D}$. A non-dimensional time step $(\Delta \mathrm{t})$ of $0.001 \mathrm{D} / \mathrm{U}_{\infty}$ is found to be sufficient, and the simulations are run for 200 non-dimensional time units $\left(\mathrm{D} / \mathrm{U}_{\infty}\right)$.
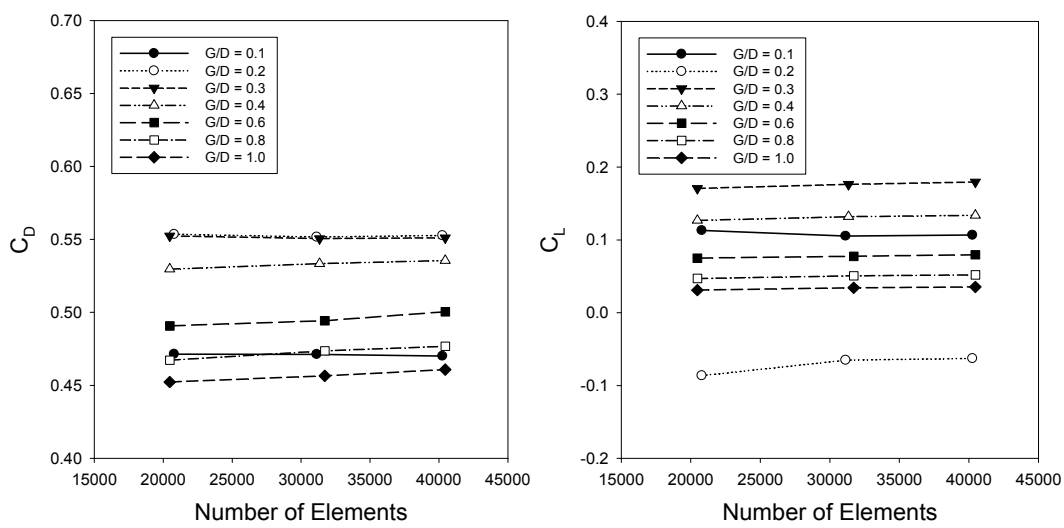

Figure 2: $\quad$ Grid convergence study for $C_{D}$ and $C_{L}$ with respect to the number of elements in the computational domain for $\mathrm{Re}=3.6 \times 10^{6}$ with $\delta / \mathrm{D}=0.48$ and $\mathrm{z}_{\mathrm{w}}=1 \times 10^{-6} \mathrm{~m}$.

\section{Results and discussion}

\subsection{Validation study}

High Reynolds number flows at $\mathrm{Re}=3.6 \times 10^{6}$ with $\delta / \mathrm{D}=0.48$ and $\mathrm{z}_{\mathrm{w}}=$ $\left(1 \times 10^{-6} \mathrm{~m}, 2 \times 10^{-5} \mathrm{~m}\right)$ are investigated numerically in the present study. In this flow regime, there are neither experimental nor numerical results available in the open literature. However, the present results are validated by comparing the present numerical results for $\mathrm{G} / \mathrm{D}=1$ with both published experimental data and numerical results for an isolated cylinder subject to a steady current in the same flow regime, since the effect of the seabed on the flow around the cylinder is insignificant for $G / D=1$. The values of $C_{D}, C_{L r m s}$ and $S t$ for $G / D=1$ and $z_{w}=$ $1 \times 10^{-6} \mathrm{~m}$ are within the range of the published experimental data and numerical results for steady flow around an isolated circular cylinder, see table 1 . 


\subsection{Vortex shedding and suppression}

Fig. 3 shows $C_{L r m s}$ versus $G / D$ for $\delta / D=0.48$ and the seabeds with $z_{w}=1 \times 10^{-6} \mathrm{~m}$ and $2 \times 10^{-5} \mathrm{~m}$. It appears that $\mathrm{C}_{\mathrm{Lrms}}$ versus $\mathrm{G} / \mathrm{D}$ has the same qualitative behaviour for both cases, but $C_{\text {Lrms }}$ is generally lower for $Z_{w}=2 \times 10^{-5} \mathrm{~m}$ (rougher bed) than for $\mathrm{z}_{\mathrm{w}}=1 \times 10^{-6} \mathrm{~m}$ for $0.15<\mathrm{G} / \mathrm{D}<0.8$. The critical value for onset of vortex shedding, $G / D_{c}$ (i.e. where the curve will intersect the horizontal axis), is between 0.1 and 0.15 in both cases, but it has not been calculated exactly here. It is observed that $G / D_{c}$ decreases when Re increases by comparing the present results with the lower $\operatorname{Re}\left(\operatorname{Re} \sim \mathrm{O}\left(10^{4}\right)\right)$ results (i.e. $\left.\mathrm{G} / \mathrm{D}_{\mathrm{c}} \sim 0.3\right)$ reported by Lei et al. [2], Ong et al. [6] and Wang and Tan [3]. Lei et al. [14] found a similar relation between $G / D_{c}$ and $R e$ for their simulations at $R e=80-1000$. In fig. 3, $C_{L r m s}=0$ at $G / D=0.1$, suggesting no vortex shedding. For $G / D>G / D_{c}$, the magnitude of $C_{\text {Lrms }}$ exhibits a rapid initial increase as G/D increases. Fig. 3 also shows that there is a transitional trough of $\mathrm{C}_{\mathrm{Lrms}}$ for $0.2<\mathrm{G} / \mathrm{D}<0.4$. This might be caused by the transition of vortex shedding development which cannot be captured correctly by the present turbulence model. For G/D > 0.4, $\mathrm{C}_{\mathrm{Lrms}}$ decreases smoothly as G/D increases, suggesting that the behaviour of the vortex shedding is rather stable.

Fig. 4 shows the instantaneous non-dimensional vorticity $\left(\omega \mathrm{D} / \mathrm{U}_{\infty}\right)$ contour plots for flows at $\operatorname{Re}=3.6 \times 10^{6}$ with $\delta / \mathrm{D}=0.48$ and $\mathrm{G} / \mathrm{D}=(0.1,0.15,0.3,0.8)$ near a bed with $\mathrm{z}_{\mathrm{w}}=1 \times 10^{-6} \mathrm{~m}$ at the non-dimensional time of $200 \mathrm{D} / \mathrm{U}_{\infty}$. Here $\omega$ is

Table 1: $\quad$ Numerical results and experimental data at $\operatorname{Re}=3.6 \times 10^{6}$.

\begin{tabular}{|c|c|c|c|c|c|}
\hline $\operatorname{Re}$ & & Description & $\mathrm{C}_{\mathrm{D}}$ & $\mathbf{C}_{\text {Lrms }}$ & St \\
\hline \multirow{4}{*}{$\begin{array}{c}3.6 \times 10^{6} \\
\text { (Upper- } \\
\text { transition } \\
\text { regime) }\end{array}$} & $\mathrm{G} / \mathrm{D}=1$ & Present simulation with $\mathrm{z}_{\mathrm{w}}=1 \times 10^{-6} \mathrm{~m}$ & 0.4608 & 0.0857 & 0.3052 \\
\hline & \multirow{3}{*}{$\begin{array}{l}\text { Flow } \\
\text { around an } \\
\text { isolated } \\
\text { cylinder }\end{array}$} & Ong et al. [8] & 0.4573 & 0.0766 & 0.3052 \\
\hline & & $\begin{array}{l}\text { Catalano et al. [9] URANS Re }= \\
\qquad 4 \times 10^{6}\end{array}$ & 0.46 & - & - \\
\hline & & $\begin{array}{c}\text { Published experimental data } \\
\text { (summarized by Zdravkovich [15]) }\end{array}$ & $\begin{array}{c}0.36- \\
0.75\end{array}$ & $\begin{array}{c}0.06- \\
0.14\end{array}$ & $\begin{array}{c}0.17- \\
0.29\end{array}$ \\
\hline
\end{tabular}

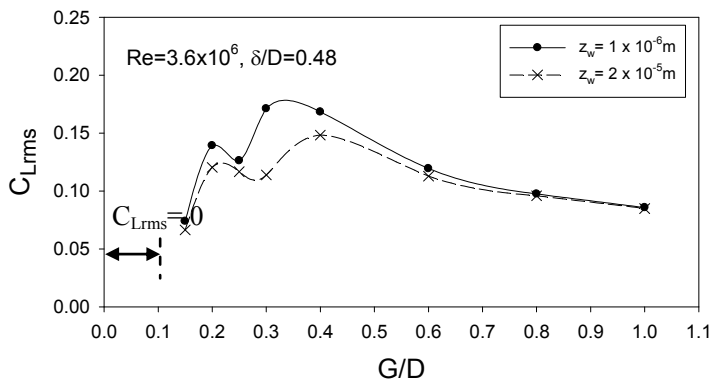

Figure 3: $\quad$ RMS value of the fluctuating lift coefficient versus gap to diameter ratio for the given values of Re, $\delta / D$ and $z_{w}$. 
(a) $\mathrm{G} / \mathrm{D}=\mathbf{0 . 1}$

Vortex-shedding suppressed

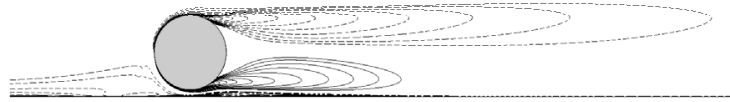

(b) $\mathrm{G} / \mathrm{D}=\mathbf{0 . 1 5}$

Vortex shedding formed and starts the interaction with the flat seabed

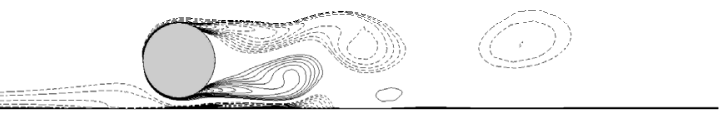

(c) $\mathrm{G} / \mathrm{D}=\mathbf{0 . 3}$

Vortex shedding formed and interacting with the flat seabed

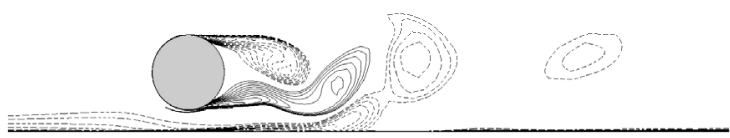

(d) $\mathrm{G} / \mathrm{D}=1$

Vortex shedding developed and interacting less with the flat seabed

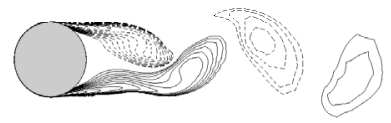

Figure 4: The development of vortex shedding shown by instantaneous nondimensional vorticity contour plots for $\mathrm{Re}=3.6 \times 10^{6}, \delta / \mathrm{D}=0.48$ and $\mathrm{z}_{\mathrm{w}}=1 \times 10^{-6} \mathrm{~m}$ at the non-dimensional time of $200 \mathrm{D} / \mathrm{U}_{\infty} .46$ contour levels of $\omega \mathrm{D} / \mathrm{U}_{\infty}$ from -540 to 540 are plotted.

the vorticity. The solid contour lines indicate the positive vorticity (counterclockwise) and the dashed lines indicate the negative vorticity (clockwise). There are three shear layers; two in the vicinity of the cylinder and one at the bed. The suppression and formation of the vortex shedding are also influenced by the interaction between these three shear layers.

It appears that there is no mutual interaction between the two shear layers from the cylinder to form any Kármán-like vortex shedding for $\mathrm{G} / \mathrm{D}=0.1$ (fig. 4a). Both shear layers continue to grow and advect downstream without forming any vortices in the near wake of the cylinder. The flow pattern remains steady. For $\mathrm{G} / \mathrm{D}=0.15$ (fig. $4 \mathrm{~b}$ ), the two shear layers have begun to interact with each 
other and form Kármán-like vortices in the near wake of the cylinder. The bottom shear layer with positive vorticity interacts with the shear layer (negative vorticity) from the flat seabed. A counter-clockwise vortex shed from the lower side of the cylinder clearly destabilizes the wall boundary layer, and it is accompanied by a clockwise vortex in the near-flat-bed region. For $G / D=0.3$ (fig. 4c), the vortex shedding behind the cylinder continues to develop. The vortex with negative vorticity (clockwise) shed from the upper shear layer, interacts with the clockwise vortex formed by the shear layer from the seabed. These two groups of vortices interact and form a larger vortex. For G/D $=1.0$ (fig. 4d), the vortices shed from the cylinder are not influenced by the shear layer at the bed. The vortex shedding is similar to the case for flow around an isolated circular cylinder (see Ong et al. [8], fig. 6). Wang and Tan [3] and Lei et al. [14] have observed a similar development of vortex shedding in both their experimental and numerical results at lower Reynolds numbers (i.e. $\operatorname{Re}<10^{5}$ ), except that the dependency of $\mathrm{G} / \mathrm{D}_{\mathrm{c}}$ is different.

\subsection{Mean pressure coefficient and friction force along the flat seabed}

Fig. 5 shows the mean pressure coefficient along the seabed $\left(C_{p w}=\left[p_{w}-\right.\right.$ $\left.\left.\mathrm{p}_{\infty}\right] /\left[0.5 \rho \mathrm{U}_{\infty}^{2}\right]\right)$ for $\mathrm{Re}=3.6 \times 10^{6}, \delta / \mathrm{D}=0.48, \mathrm{z}_{\mathrm{w}}=1 \times 10^{-6} \mathrm{~m}$ and $\mathrm{G} / \mathrm{D}=(0.1,0.4$, 0.8 ). Here $\mathrm{p}_{\mathrm{w}}$ is the pressure along the seabed. $\mathrm{C}_{\mathrm{pw}}$ is substantially influenced by the existence of the cylinder. For a small gap, i.e. $G / D=0.1$, it appears that the pressure suction at the gap $(\mathrm{X}=0)$ is large compared with those for $\mathrm{G} / \mathrm{D}=0.4$ and 0.8 . Here $\mathrm{X}$ is the horizontal coordinate along the flat seabed where $\mathrm{X}=0$ is located at the centre of the gap, see fig. 1. This is mainly due to the higher magnitude of the velocity at the gap when G/D is small as shown in fig. 6 (which shows the velocity profile at the centre of the gap for $\mathrm{G} / \mathrm{D}=0.1,0.4$ and 0.8 ). This feature is similar to the lower $\mathrm{Re}$ results $\left(\mathrm{Re}=4.8 \times 10^{4}\right)$ reported by Bearman and Zdravkovich [1] and Ong et al. [6]. Fig. 7 shows that the effect of the seabed roughness (with $\mathrm{Z}_{\mathrm{w}}=2 \times 10^{-5} \mathrm{~m}$ ) on $\mathrm{C}_{\mathrm{pw}}$ is insignificant as compared with the results for $\mathrm{z}_{\mathrm{w}}=1 \times 10^{-6} \mathrm{~m}$.

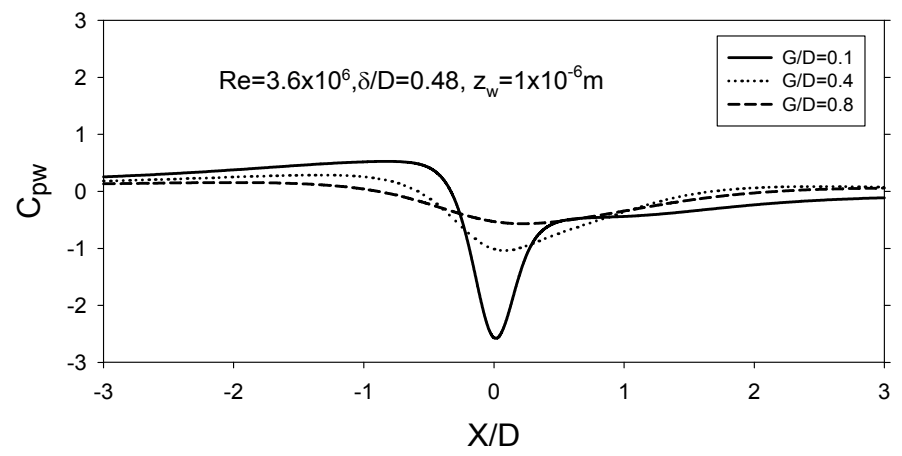

Figure 5: Mean pressure coefficient along the flat seabed for the given values of $\mathrm{Re}, \delta / \mathrm{D}$ and $\mathrm{G} / \mathrm{D}$. 

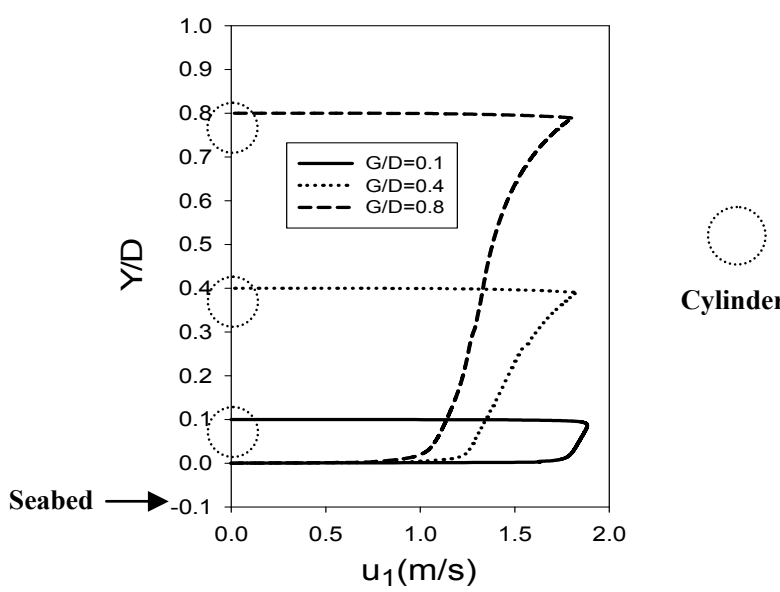

Cylinder

Figure 6: Instantaneous horizontal velocity profile in the gap for $\mathrm{Re}=$ $3.6 \times 10^{6}, \delta / \mathrm{D}=0.48, \mathrm{z}_{\mathrm{w}}=1 \times 10^{-6} \mathrm{~m}$ and $\mathrm{G} / \mathrm{D}=(0.1,0.4,0.8)$ at the non-dimensional time of $200 \mathrm{D} / \mathrm{U}_{\infty}$.

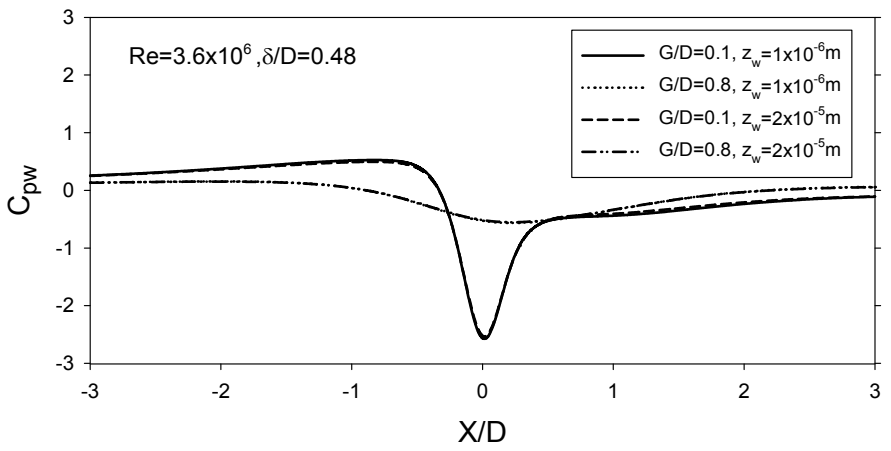

Figure 7: $\quad$ Mean pressure coefficient along the flat seabed for the given values of $\mathrm{Re}, \delta / \mathrm{D}, \mathrm{z}_{\mathrm{w}}$ and $\mathrm{G} / \mathrm{D}$.

Fig. 8 shows the mean friction velocity $\left(\mathrm{u}_{*}{ }_{w m}\right)$ for $\mathrm{Re}=3.6 \times 10^{6}, \delta / \mathrm{D}=0.48$, $\mathrm{G} / \mathrm{D}=(0.1,0.8)$ and $\mathrm{z}_{\mathrm{w}}=\left(1 \times 10^{-6} \mathrm{~m}, 2 \times 10^{-5} \mathrm{~m}\right)$. It is observed that $\mathrm{u}_{*_{\mathrm{wm}}}$ is higher for the rougher seabed $\left(\mathrm{z}_{\mathrm{W}}=2 \times 10^{-5} \mathrm{~m}\right)$ than that for the less rough seabed $\left(\mathrm{z}_{\mathrm{w}}=\right.$ $\left.1 \times 10^{-6} \mathrm{~m}\right)$, as expected. Fig. 8 also shows that $\mathrm{u}_{* \mathrm{wm}}$ at the gap is much higher for $\mathrm{G} / \mathrm{D}=0.1$ than that for $\mathrm{G} / \mathrm{D}=0.8$. This is due to the higher velocity at the gap when $\mathrm{G} / \mathrm{D}$ is small as shown in fig. 6 .

\subsection{An example of bedload sediment transport calculation}

The calculation of the bedload sediment transport along the flat seabed is demonstrated in this section. The instantaneous non-dimension bedload sediment transport $\Phi$ is a function of the instantaneous non-dimensional seabed shear stress (Shields parameter) $\theta_{\mathrm{s}}$ and is given by (Nielsen [16]) 
where

$$
\Phi=12\left|\theta_{s}\right|^{1 / 2}\left(\theta_{s}-\theta_{s c}\right) \frac{\theta_{s}}{\left|\theta_{s}\right|}
$$

$$
\begin{aligned}
& \Phi=\frac{q_{b}}{\left(g(s-1) d_{50}{ }^{3}\right)^{1 / 2}} \\
& \theta_{\mathrm{s}}=\frac{u_{*_{w}}^{2}}{g(s-1) d_{50}}
\end{aligned}
$$

Here $\mathrm{q}_{\mathrm{b}}$ is the instantaneous dimensional bedload sediment transport, $\mathrm{g}=$ $9.81 \mathrm{~m} / \mathrm{s}^{2}$ is the gravitational acceleration and $\mathrm{s}=2.65$ is the density ratio between the bottom sediments and the water (taken as for quartz sand). The critical Shields parameter $\theta_{\mathrm{sc}}=0.05$ must be exceeded for bedload transport to occur.

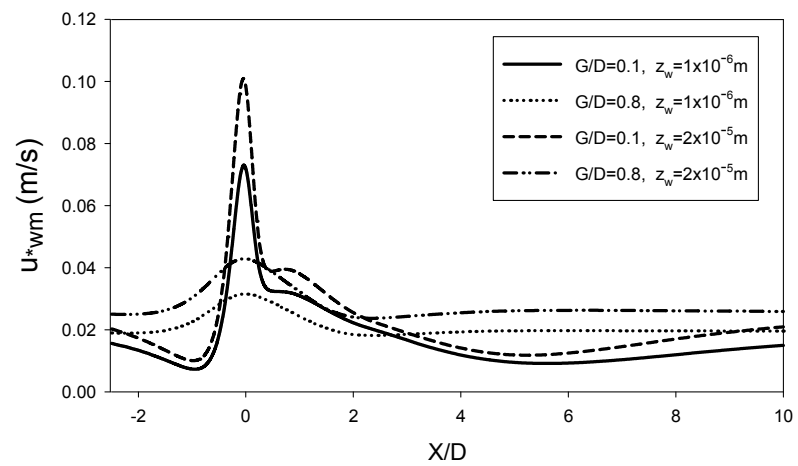

Figure 8: Mean friction velocity along the flat seabed for $\operatorname{Re}=3.6 \times 10^{6}, \delta / \mathrm{D}$ $=0.48, \mathrm{z}_{\mathrm{w}}=\left(1 \times 10^{-6} \mathrm{~m}, 2 \times 10^{-5} \mathrm{~m}\right)$ and $\mathrm{G} / \mathrm{D}=(0.1,0.8)$.

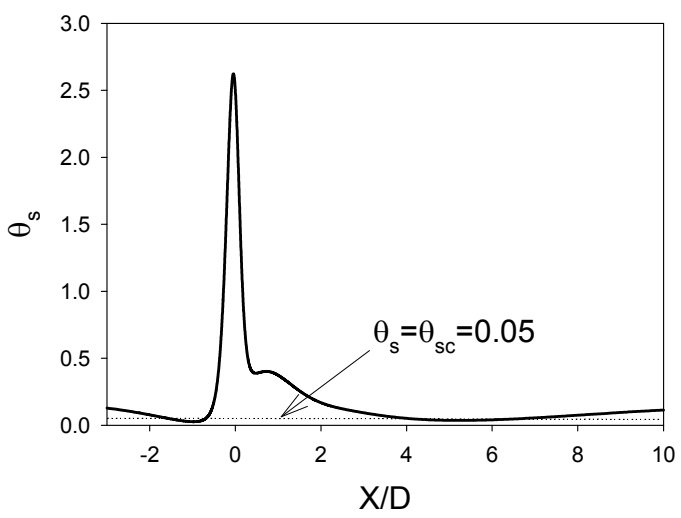

Figure 9: Instantaneous Shields parameter along the seabed for $\mathrm{Re}=$ $3.6 \times 10^{6}, \delta / \mathrm{D}=0.48, \mathrm{z}_{\mathrm{w}}=2 \times 10^{-5} \mathrm{~m}$ and $\mathrm{G} / \mathrm{D}=0.1$. 


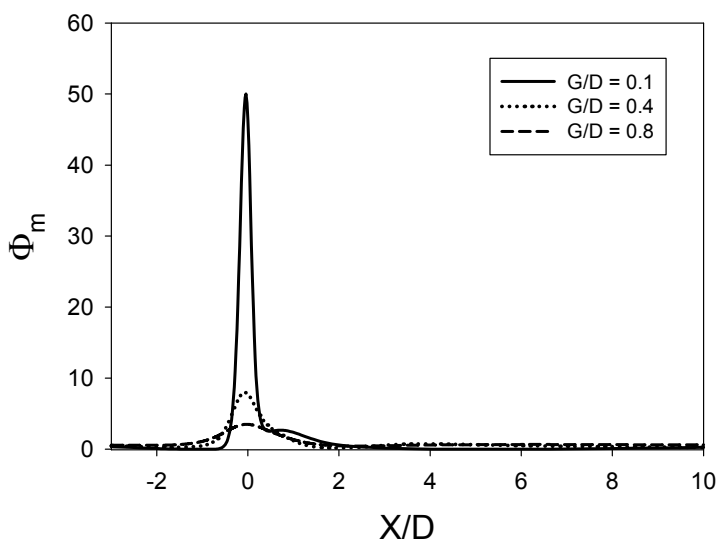

Figure 10: Mean non-dimensional bedload sediment transport along the bed for $\mathrm{Re}=3.6 \times 10^{6}, \delta / \mathrm{D}=0.48, \mathrm{z}_{\mathrm{w}}=2 \times 10^{-5} \mathrm{~m}$ and $\mathrm{G} / \mathrm{D}=(0.1,0.4$, $0.8)$.

Fig. 9 shows $\theta_{\mathrm{s}}$ along the flat seabed for $\mathrm{Re}=3.6 \times 10^{6}, \delta / \mathrm{D}=0.48, \mathrm{z}_{\mathrm{w}}=$ $2 \times 10^{-5} \mathrm{~m}$ (i.e. $\mathrm{d}_{50}=12 \mathrm{z}_{\mathrm{w}}=0.24 \mathrm{~mm}$, fine sand) and $\mathrm{G} / \mathrm{D}=0.1$. The locations where the sediment transport takes place for $\theta_{\mathrm{s}}>\theta_{\mathrm{sc}}$ can be determined from the figure. Fig. 10 shows $\Phi_{\mathrm{m}}$ (the mean non-dimensional bedload transport) along the bed for $\operatorname{Re}=3.6 \times 10^{6}, \delta / D=0.48, z_{w}=2 \times 10^{-5} \mathrm{~m}$ and $\mathrm{G} / \mathrm{D}=(0.1,0.4,0.8)$. It is observed that the bedload sediment transport is significantly amplified at the location of the gap $(X / D=0)$ for $G / D=0.1$ compared with those for $G / D=0.4$ and 0.8. If the flat seabed is movable, scouring around the cylinder will take place. The scouring process will not be investigated here. Detailed explanations of the flow mechanisms and the development of the scour can be found in Sumer and Fredsøe [17].

\section{Conclusions}

Near-bed flow mechanisms of high Reynolds number flows around a marine pipeline close to a flat seabed have been studied using a 2D standard high Reynolds number k- $\varepsilon$ model. The main results are summarized as follows:

1. Suppression and formation of the vortex shedding are influenced by the interaction between three shear layers; two from the top and the bottom of the cylinder and one at the seabed. The vortex shedding is suppressed when the gap is smaller than the critical gap (i.e. corresponding to the onset of vortex shedding). Beyond the critical gap, vortex shedding develops as the gap increases, and becomes fully developed as the influence of the bed diminishes.

2. For the same Reynolds number, inlet boundary layer thickness, seabed roughness and cylinder, the magnitude of negative pressure coefficient at the seabed at the location of the gap increases as the gap becomes smaller. 
3. The mean friction velocity at the gap (at the seabed) is much larger for small gaps than for large gaps. This is due to the higher velocities within the gap when the gap is small. As a consequence, the bedload sediment transport is much larger for small gaps than for large gaps.

Overall it appears that the present approach is suitable for design purposes at high Reynolds numbers which are present near the seabed in the real ocean. However, experimental data are required in order to perform a more detailed validation study of the model.

\section{References}

[1] Bearman, P.W. \& Zdravkovich, M.M., Flow around a circular cylinder near a plane boundary. J. Fluid Mech., 89(1), pp. 33-47, 1978.

[2] Lei, C., Cheng, L. \& Kavanagh, K., Re-examination of the effect of a plane boundary on force and vortex shedding of a circular cylinder. J. Wind Eng. \& Ind. Aerodynamics, 80(3), pp. 263-286, 1999.

[3] Wang, X. \& Tan, S.K., Near-wake flow characteristics of a circular cylinder close to a wall. J. Fluids \& Struc., 24(5), pp. 605-627, 2008.

[4] Brørs, B., Numerical modelling of flow and scour at pipelines. J. Hydraulic Eng., 125(5), pp. 511-523, 1999.

[5] Zhao, M., Cheng, L. \& Teng, B., Numerical modelling of flow and hydrodynamics forces around a piggyback pipeline near the seabed. $J$. Waterway, Port, Coast. \& Ocean Eng., 133(4), pp. 286-295, 2007.

[6] Ong, M.C., Utnes, T., Holmedal, L.E., Myrhaug, D. \& Pettersen, B., Numerical simulation of flow around a marine pipeline close to the seabed. Proc. $31^{\text {st }}$ Int. Conf. Coast. Eng., Hamburg, Germany, 2008. (In press).

[7] Mittal, R. \& Balachandar, S., Effect of three-dimensionality on the lift and drag of nominally two-dimensional cylinders. Phys. Fluids, 7, pp. 18411865, 1995.

[8] Ong, M.C., Utnes, T., Holmedal, L.E., Myrhaug, D. \& Pettersen, B., Numerical simulation of flow around a smooth circular cylinder at very high Reynolds numbers. Marine Struc., 22, pp. 142-153, 2009.

[9] Catalano, P., Wang, M., Iaccarino, G. \& Moin, P., Numerical simulation of the flow around a circular cylinder at high Reynolds numbers. Int. J. Heat \& Fluid Flow, 24, pp. 463-469, 2003.

[10] Launder, B.E. \& Spalding, D.B., Mathematical Models of Turbulence, Academic Press, London, 1972.

[11] Utnes, T., A segregated implicit pressure projection method for incompressible flows. J. Comp. Phys., 227, pp. 2198-2211, 2008.

[12] Gresho, P.M. \& Sani, R.L., Incompressible flow and the finite element method, John Wiley \& Sons Ltd, West Sussex, England, 1999.

[13] Rodi, W., Turbulence models and their application in hydraulics. A stateof-the-art review. IAHR Monograph Series, $3^{\text {rd }}$ Ed., A.A. Balkema, Rotterdam, The Netherlands, 1993.

[14] Lei, C., Cheng, L., Armfield, S.W. \& Kavanagh, K., Vortex shedding suppression for flow over a circular cylinder near a plane boundary. Ocean Eng., 27, pp.1109-1127, 2000. 
[15] Zdravkovich, M.M., Flow around Circular Cylinders, Vol. 1: Fundamentals, Oxford University Press, New York, 1997.

[16] Nielsen, P., Coastal Bottom Boundary Layers and Sediment Transport, World Scientific, Singapore, 1992.

[17] Sumer, B.M. \& Fredsøe, J., The Mechanics of Scour in the Marine Environment: Advanced series on ocean engineering-Vol. 17, World Scientific, Singapore, 2002. 